\title{
What is My Role in Changing the System? A New Model of Responsibility for Structural Injustice
}

\author{
Robin Zheng ${ }^{1}$ (D)
}

Accepted: 25 April 2018 / Published online: 12 May 2018

(C) The Author(s) 2018

\begin{abstract}
What responsibility do individuals bear for structural injustice? Iris Marion Young has offered the most fully developed account to date, the Social Connections Model. She argues that we all bear responsibility because we each causally contribute to structural processes that produce injustice. My aim in this article is to motivate and defend an alternative account that improves on Young's model by addressing five fundamental challenges faced by any such theory. The core idea of what I call the "Role-Ideal Model" is that we are each responsible for structural injustice through and in virtue of our social roles, i.e. our roles as parents, colleagues, employers, citizens, etc., because roles are the site where structure meets agency. In short, the Role-Ideal Model (1) explains how individual action contributes to structural change, (2) justifies demands for action from each particular agent, (3) specifies what kinds of acts should be undertaken, (4) moderates between demanding too much and too little of individual agents, and (5) provides an account of the critical responses appropriate for holding individuals accountable for structural injustice.
\end{abstract}

Keywords Moral responsibility $\cdot$ Structural injustice $\cdot$ Social roles $\cdot$ Social change

\section{Introduction}

Very few of us would say that we live in a morally just world. Most of us are deeply concerned about some issue of pressing importance or other: poverty, unemployment, racial and sexual violence, or climate change, to name just a few. These are forms of structural injustice. Structural injustice is highly complex, with multiple causes and without easy solutions. Its defining feature is that it is not maintained purely through the biased attitudes or malicious actions of individuals, though such bias and malice undoubtedly exist (cf. Haslanger 2015). Rather, structural injustice is maintained through the behavior of ordinary decent people whose

Robin Zheng

robin.zheng@yale-nus.edu.sg

1 Division of Humanities, Yale-NUS College, 28 College Avenue West \#01-501, Singapore 138533, Singapore 
choices are constrained by existing social, political, economic, and cultural institutions. Racial and class segregation, for instance, is maintained as much by well-intentioned parents seeking the best school district for their children as it is by bigoted real estate agents or landlords.

What is needed to rectify structural injustice is not (merely) that people modify their individual actions and attitudes, but that we radically transform an entire complex of interlocking structures, i.e. the system itself. This task can easily feel overwhelming, all the more so when we recognize how our everyday activities - the food we eat, the clothes we wear, the work we perform, the media we consume - perpetuate injustice. Why should I, a single individual, be held responsible for such sweeping harms? Given my total enmeshment in the system, how can I be expected to change it? This is the problem of individual responsibility for structural injustice.

Iris Marion Young has offered the most developed account to date of responsibility for structural injustices: the "Social Connections Model" (SCM). She argues that we all bear responsibility because we each causally contribute to structural processes that produce injustice. My aim in this article is to motivate and defend an alternative account that improves on Young's model by addressing five fundamental challenges faced by any such theory. The core idea is that we are each responsible for structural injustice through and in virtue of our social roles, i.e. our roles as parents, colleagues, employers, citizens, etc., because roles are the site where structure meets agency.

My plan is as follows. I begin in section 2 by introducing the structuralist approach to injustice. I then present in section 3 the main concepts and key features of the "Role-Ideal Model" (RIM), according to which individuals bear responsibility for collectively transforming social structures because of the social roles we occupy. In section 4, I compare the SCM and RIM against five desiderata that should be met by any acceptable theory of individual responsibility for structural injustice. Finally, I address potential objections in section 5. In short, the RIM (1) explains how individual action contributes to structural change, (2) justifies demands for action from each particular agent, (3) specifies what kinds of acts should be undertaken, (4) moderates between demanding too much and too little of individual agents, and (5) provides an account of the critical responses appropriate for holding individuals accountable for structural injustice.

\section{The Structural Turn}

I begin with a clarification about my use of the term "structural injustice," which is grounded in what I call "the intersectionality thesis." The intersectionality thesis, born of decades of work in feminist, critical race, postcolonial, and ethnic studies, is the claim that different oppressions $^{1}$ co-constitute and mutually reinforce one another. Its upshot is that we cannot address one oppression without addressing other oppressions. To truly care about women, for

\footnotetext{
${ }^{1}$ What is an "oppression"? On my view, many things that are wrong with the world - poverty, unemployment, homelessness, drug addiction, mass incarceration, war, rape, domestic violence, unwanted pregnancy, human trafficking, forced prostitution, refugee and immigration crises, wage gaps, environmental degradation, climate change - are what we might call "first-order problems" (which most would agree are problematic). Insofar as we do not take their existence to be uncontrollable and inevitable facts of life, however, we typically explain these with reference to (more contentious) higher-order categories such as racism, sexism, exploitation, imperialism, homo/transphobia, xenophobia, ableism, and anthropocentrism. The latter are what I will call "oppressions," by which I mean the ways in which certain social groups exercise power over others. Note that not all first-order problems are best conceived of as oppressions in this sense, though they can certainly be understood as the products of various, intersecting oppressions. My use of "structural injustice" is thus slightly distinct from though not incompatible with Young's, which seems to cover both first-order problems and oppressions.
} 
instance, one must care about poor women, women of color, LGBT women, and disabled women; hence one must care about rectifying poverty, racism, homophobia, transphobia, and ableism. Relatedly, efforts to rectify a single dimension of oppression often do not address - or can even further entrench - other dimensions of oppression. White women may be oppressed by men, for instance, but may themselves oppress Black women. Taking intersectionality seriously thus necessitates the use of some concept to designate the entire complex of oppressions as a whole (cf. Collins 1990/2000, "matrix of domination"). As I shall use it, then, the term "structural injustice" refers to the sum total of oppressions, and the ways in which they interact with and compound one another, taken holistically. And I shall take for granted that the basic intersectionality thesis is correct: if one cares about some pressing social problem, a sufficiently deep enough understanding of that problem will eventually require that one cares about structural injustice as a whole.

In what follows, I situate Young's structuralist approach to injustice in the context of two broader trends in recent work on responsibility for injustice.

\subsection{From Agents to Structures}

Traditional theorizing about injustice has been premised on a picture of individual moral agents bearing responsibility for particular actions because they exercise freedom and rationality in choosing to act one way rather than another. Recent thinking, however, has been characterized by a move away from agents to structures, as suggested by the term "structural injustice" itself. This turn to structure, as it might be called, represents an important theoretical break from two previous approaches, which I briefly canvass here.

The "aggregative approach" seeks to understand individual responsibility for structural injustices in terms of agents' relationships to collective agents ${ }^{2}-$ e.g. states, the military, corporations - that have power to perform actions that individual agents cannot, but are still relevantly similar in possessing distinctive features of moral agency (see, e.g. French 1984). Responsibility might then be distributed back down to the individuals of which collective agents are composed (Collins and Lawford-Smith 2016); alternatively, individuals are said to be responsible in virtue of their capacities to form a collective agent (Collins 2013; Held 1970; Isaacs 2011). On the "individualist approach," the strategy is to identify some independently plausible moral principle and adapt it in the context of structural injustices: principles of restitution, unjust enrichment, or complicity (Boxill 2003; Butt 2009; Calder 2010; Kutz 2000; Mellema 2016) or duties of assistance (Singer 1972).

A "structuralist approach," by contrast, rejects the conception of the liberal autonomous subject underlying the traditional picture of responsibility (Haslanger 2015; Lavin 2008; Young 2011). It highlights instead the way in which social life is characterized by pervasive pressures constraining the range of agents' possible actions. For structuralists, the aggregative approach falls short because, even though collectives are powerful, they still face structural constraints. For example, corporations operate sweatshops because their profits and viability are threatened when their competitors cut costs, and governments in developing countries permit them because their attractiveness to foreign investors - vital for surviving in a global capitalist order - is threatened when they tighten labor regulations and others do not (Young 2011). Vis-a-vis the individualist approach, structural

\footnotetext{
${ }^{2}$ Another version focuses on social groups lacking full-fledged collective agency but whose members are bound together strongly enough through shared attitudes, interests, or identities that harms inflicted by some members reflect on the entire whole (Feinberg 1968; May 1992; McGary 1986).
} 
constraints explain why agents for the most part do not live up to the stringent demands of these moral principles: it is not that they are bad or immoral people, but that they are beset by other pressures - as with the parents trying to provide the best possible education for children destined for tough job markets. A lucid appreciation of these ubiquitous constraints makes clear that the structures within which agents make their choices are just as important as the choices themselves, and that those choices quite often will not reflect what an agent would freely and rationally choose if she had other options.

The move to structures yields two immediate theoretical advantages. First, it expands the scope of possible objects of moral responsibility. Rather than merely ascribing responsibility for discrete events ${ }^{3}$ (a particular police shooting, say), we can also ascribe responsibility for the background conditions against which these events take place (anti-black stereotypes, racial ghettoization, austere economic conditions in which poverty begets crime). Second, it greatly enlarges the set of subjects that can be considered responsible. Rather than designating and setting apart some individual or group as "guilty," while exonerating others as "not responsible," a structuralist approach can recognize multiple - indeed all - parties that are implicated. For oppressive structures are perpetuated by the ongoing behaviors of all participants, albeit in different ways; they are enacted and re-enacted by sweatshop laborers in addition to corporations and governments (Young 2011). And they cannot be transformed by the act of one individual or collective agent, no matter how powerful.

\subsection{From Attributability to Accountability}

The immediate problem that follows, however, is that we seem to lose our grip on responsibility. When we say that injustice is caused by structures and not agents, are we saying that no one is responsible? To address this problem, structuralists rely on another key move: distinguishing between different types of responsibility. In addition to Young, political philosophers have contrasted "blame-responsibility" vs. "task-responsibility" (Schmidtz and Goodin 1998), "liberal" vs. "postliberal" responsibility (Lavin 2008), and "outcome responsibility" vs. "remedial responsibility" (Miller 2007). In each pair, the latter concept used for structural injustice is characterized as forward- rather than backward-looking, as politically assigned rather than discovered, as potentially grounded in factors other than moral desert or causing harm, and hence as not functioning to allocate blame or punishment.

I have argued elsewhere that these all represent different interpretations of a longstanding distinction from the moral responsibility literature between the concepts of responsibility as "attributability" and responsibility as "accountability," which arise from two distinct sources of philosophical concern (Zheng 2016). Attributability derives from a fundamentally metaphysical and action-theoretic problem concerning what actions count as genuine exercises of agency, because only those can provide legitimate grounds for blaming or punishing a person. The liability model of responsibility, liberal responsibility, blame-responsibility, and outcome responsibility thus represent particular conceptions of attributability. Accountability, however, concerns a moral and political (rather than metaphysical) problem. When a person fails to carry out a duty, the burdens of redress must be distributed across the community somehow or other; and it is sometimes appropriate to place burdens on an agent even if it did not result from a

\footnotetext{
${ }^{3}$ This remains necessary and important. Much evil in the world is undoubtedly attributable to wrongful actions of individuals. But the point is that even without them, existing structural constraints would still generate unjust outcomes (Haslanger 2015).
} 
faulty exercise of agency. The social connection model of responsibility, postliberal responsibility, task-responsibility, and remedial responsibility, then, represent particular conceptions of accountability.

The move from attributability to accountability thus avoids the philosophical difficulties that beset the aggregative and individualist approaches, which stem from trying to ascribe attributability for structural injustice. While such accounts are insightful and compelling, they often remain philosophically contentious because they must establish the traditional conditions of responsibility: that an agent caused harm knowingly and voluntarily. By contrast, agents need not meet the high bar required for blame and punishment to bear accountability.

\section{The Role-Ideal Model of Accountability}

I now propose an alternative structuralist model of individual responsibility for structural injustice, which I call the "Role-Ideal Model" (RIM). The core idea is that we are, each of us, individually responsible for structural injustice through and in virtue of our social roles. Like the SCM, the RIM does not wholly replace attributability models of responsibility, which perform important functions in certain contexts. Individuals certainly can be attributively responsible and hence deserve blame or punishment for (some part of) structural injustice, but this is usually difficult to establish outside particularly egregious cases; the RIM establishes that we are all still accountable for injustice even though we are structurally constrained. ${ }^{4}$ Extensionally, the RIM does not differ from the SCM: just as everyone is inextricably causally implicated in producing unjust outcomes, so too does everyone unavoidably occupy (multiple) social roles. Theoretically, however, the shift to social roles makes for a stronger model because the very concept of "social role" comes ready-made, as it were, with a suite of features that make it eminently suitable for addressing structural injustice.

What is a social role? In line with traditional sociological theory (e.g. Dahrendorf 1968), I define it as follows:

Social role: A social role $\boldsymbol{R}$ is a set of expectations $\boldsymbol{E}$ - predictive and normative - that apply to an individual $\boldsymbol{P}$ in virtue of a set of relationships $\boldsymbol{P}$ has with others (such that anyone standing in the same type of relationships as $\boldsymbol{P}$ occupies the same $\boldsymbol{R}$ ), and where

$\boldsymbol{E}$ is mutually maintained by $\boldsymbol{P}$ and others through a variety of sanctions.

The expectations are predictive in the sense that they are beliefs about how a person will act and be (in specific contexts), and they are normative in the sense that they are beliefs about how she should act and be. The set of relationships with others, which might each be designated "role-segments," are the definitive elements of the role: the role of "teacher," for instance, comprises specific relationships with students, students' parents, the school principal, members of the teachers' union, education policymakers, and so on (Gross et al. 1958). For each role-segment, e.g. "teacher-student," there are distinctive forms of behavior and attitude that are intelligible and appropriate between parties in that relationship. It is intelligible and appropriate for a teacher to instruct the student to perform academic exercises, feel concern when the work is poor, and so on. Conversely, the "student-teacher" role-segment of the

\footnotetext{
${ }^{4}$ As an alternative conception of accountability, the RIM is in principle compatible with the SCM, that is, we may be accountable for structural injustice for more than one reason. However, as I explain in Section 4, the RIM has certain advantages over the SCM. I am grateful to an anonymous reviewer for pushing me to clarify these points.
} 
"student" role makes it intelligible and appropriate for the student to ask for assistance with exercises, request feedback, and so on. These are some of the expectations that constitute the social roles of "student" and "teacher," and our expectations of others standing in the same nexus of relationships will be relevantly similar. Finally, the sanctions in question can be positive or negative, formal or informal, material or psychological, and imposed by others from the outside or via the person's own sensibilities. When our expectations of a teacher are satisfied or unsatisfied, we might respond variously with grateful phone calls or angry emails, a "Teacher of the Year" award or suspension and dock in pay; the teacher herself may feel pride when her students perform well, and guilt when she worries she has not sufficiently prepared them for some assessment.

Within sociological theory, two main traditions have explored the idea that social roles are the interface between social structure and individual agency. While structural-functionalism focuses on the way roles constrain agency, symbolic interactionism emphasizes how roles enable agency.

Structural-functionalist (or "system") theories are primarily concerned with the problem of social order: how is that societies for the most part hold together as continuously and smoothly as they do, and in much the same form? (Black 1961; Parsons 1951/1991). Their primary metaphor is that of an organism composed of head, limbs, organs, and so on functioning together to ensure biological survival. Role differentiation is what makes it possible for the assorted members of a society to carry out, in a structured and coordinated way, all the functions necessary for society to sustain itself. On this view, social structures are maintained through interlinked processes of socialization (internalization of system requirements) and sanctions (which are positive when behavior conforms to expectations and negative when it deviates) that keep people in their respective roles. Viewed as an organic whole, society thus functions as a boundary-maintaining system: when some people deviate from their roles, the rest of the system works to restore order, just as a homeostatic organism works to maintain a constant temperature, blood flow, and so on.

According to the RIM, then, individuals are responsible in the accountability sense for fulfilling their social roles, where the expectations of each role spells out certain duties to be performed and certain sanctions to be incurred in the event of non-performance. Moreover, it is through performing a social role that an individual (together with others) enacts structure. This marks an important difference between the SCM and the RIM. On the SCM, individuals are responsible for unjust outcomes because of their causal contributions to structural processes. By contrast, the RIM maintains that individuals are responsible because their role performances are what constitute unjust structures. This distinction between causation and constitution is subtle, but important. On the SCM, individuals can try to avoid responsibility by denying that they have any backward-looking causal connections or forward-looking ability to control structural processes. On the RIM, by contrast, whether an individual's action makes a causal difference or not is beside the point: their performance of roles partially constitutes the unjust structure. Therefore that individual is accountable (together with others) for that social structure, and when it is unjust, they appropriately bear the burdens of reforming it.

Although this idea of social roles is simple, their reality is far more complex. This fact is exemplified by theories of symbolic interactionism. The idea, put simply, is that social structures are built up from micro-level interpersonal interactions which are continually negotiated, enacted, and re-enacted (see, e.g. Goffman 1959). Recall that a social role is built up of different expectations compiled from its role-segments. These expectations never fully specify in complete detail exactly what the occupier is supposed to do, and expectations from different 
(or within) role-segments never perfectly overlap; roles are thus in some sense essentially indefinable. Because "roles" by definition must be such as to allow different individuals to occupy the same role, there is a limit to how much content can be built into the role: it cannot require that some role-defining task $\mathrm{R}$ be performed only by doing $\mathrm{A}, \mathrm{B}$, and $\mathrm{C}$ because it must be possible for others occupying the same role in different circumstances and with different abilities to achieve $\mathrm{R}$ through alternative means $\mathrm{X}$, Y, or Z. ${ }^{5}$ Performing a role, then, is an ongoing process of making infinitely many tiny decisions about how to perform it, thereby calibrating one's behavior with another's expectations and behavior at the same time that the other is calibrating their expectations and behavior with yours (cf. MacIntyre 1999). While expectations stabilize over time into familiar roles, they must also be renewed with each new iteration. Equally important to the RIM, then, is the concept of a role-ideal:

Role-Ideal: For every social role $R$ occupied by an individual $P$, a role-ideal is $P$ 's interpretation of how she could best satisfy the expectations constituting $R$ (based on $P$ 's own beliefs, values, commitments, abilities, and lived experience).

In other words, a role-ideal is P's personal conception of what makes a good R. Role-ideals are importantly different from social roles because the content of social roles is in large part intersubjectively shared, whereas role-ideals can vary greatly from person to person. While $\mathrm{M}$ may believe that a good teacher maintains clear and professional boundaries with students, takes attendance, and adheres to a well-defined agenda, $\mathrm{N}$ may believe that a good teacher behaves "like one of the guys," swaps jokes and anecdotes with students, and is lenient about absences. $\mathrm{M}$ and $\mathrm{N}$ may construct different role-ideals because they have different pedagogical priorities, or because they possess different social identities (e.g. gender, age, nationality) that raise different student-facing challenges.

Social roles come in many types, and every individual occupies multiple roles at any given time (Dahrendorf 1968; Parsons 1951/1991). They may be "specific," in the sense that they are bound to relatively short-lived and circumscribed contexts, like "bystander" or "bus rider," or they may be "diffuse," in the sense that they govern all contexts, like "woman" or "Muslim." They may be "ascribed" on the basis of what one is, as in categories defined by race and age, or they may be "achieved" as a result of what one does, as with professor or rock climber. And they may be "formal" roles possessing explicit, institutionalized expectations, or they may not, in which case they are "informal." This flexibility and multiplicity of roles, combined with their indefinability, make it impossible to predict how a given person will act in negotiating the specific combination of roles they occupy. But individuals are typically highly motivated to act in accordance with at least some of their role-ideals. When a person identifies with a role (usually through socialization) it becomes intrinsically gratifying to satisfy role expectations; this is part of what enables roles to preserve social structure (Dahrendorf 1968; Parsons 1951/ 1991). On the RIM, it is this simultaneous psychological and normative force of role-ideals that connects individual agency to social structure in such a way as to ground moral responsibility.

\section{Five Desiderata: The SCM vs. RIM}

Like Young's SCM, the Role-Ideal Model (RIM) is a structuralist approach that locates the wrongs of structural injustice in structures, rather than individual agents; and like the SCM, the

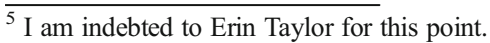


type of responsibility in question is accountability rather than attributability. However, the RIM differs in a number of key respects. Here, I break down the problem into five practical questions corresponding to distinct theoretical challenges for which any acceptable model should provide answers, and I use them to illustrate the differences between Young's SCM and the RIM.

\subsection{The Question of Social Change: How Can My Actions Produce Structural Change?}

An acceptable model must clearly explain how individual agency impacts social structure. Responsibility requires agency. But the more that structures are thought to determine individuals' choices, the less agency they seem to possess. Moreover, responsibility also requires ability: one cannot be responsible for something that one simply isn't able to perform. Yet structural injustice cannot be undone through the actions of any particular agent.

The SCM addresses the ability requirement by stating explicitly that the responsibility in question can only be discharged through collective action. What individuals are responsible for - what is within their ability - is "joining with others to organize collective action" (Young 2011). Individuals are capable of educating themselves, persuading others to act, and so on. However, the SCM does not yet fully explain how it is that these actions might generate structural transformation. Young has surprisingly little to say on the subject, more or less summed up in the following sentence: "Social change requires first taking special efforts to make a break in [structural] processes, by engaging in public discussions that reflect on their workings, publicizing the harms that come to persons who are disadvantaged by them, and criticizing powerful agents who encourage the injustices or at least allow them to happen" (Young 2011). In essence, her picture is one of pressuring powerful agents. But, as noted earlier, powerful agents also face structural constraints, and no agent, however powerful, is singlehandedly capable of transforming the structures within which it acts. While this model represents one important way in which social change occurs, then, it has limitations and remains somewhat individualist in its scope. A truly structuralist approach should envisage other ways of pressuring the system.

The RIM tackles the problem of social change head on, though this may seem counterintuitive, since it might be thought that social roles are precisely the problem, i.e. the reason why structural injustice persists. Indeed, structural-functionalism has been criticized as an inherently conservative theory that came to prominence during the 1950s and 1960s through its insistence on the necessity and desirability of social conformity against resistance movements seeking radical change (Connell 1979). Young herself points out that existing roles serve to preserve an unjust system while rationalizing individuals' maintenance of the status quo. She thus explicitly rejects the idea that responsibility for injustice is grounded in social roles, proposing that it is instead a "responsibility in general as [participants of social processes]" (Young 2011).

Yet I believe that the concept of social roles - the site where structure meets agency - is too important to jettison. Structural-functionalism provides crucial insights into the immense challenge of radical, wholesale structural transformation. What has become apparent through the twentieth century is that even drastic changes in one sub-system (e.g. political revolution) typically do not lead to lasting or widespread change if pressures from other subsystems (e.g. the global economic order) push back toward equilibrium. To recast the intersectionality thesis into structural-functionalist terminology, we might say: the problem is that modifying one sub-system (economic, legal, political; race, gender, class) is merely 
change within the system, but does not constitute change of the system, ${ }^{6}$ and often languishes in the face of boundary-maintaining pressures.

Moreover, because social roles maintain structures, they can also be used to transform them. This transformative potential is most apparent in symbolic interactionist theories of roles. A key metaphor in the literature is of role as resource (Baker and Faulkner 1991; Callero 1994). In occupying a role, individuals acquire access to specific resources and powers. In my role as "professor," for instance, I can gain entry into the university library, request an audience with the dean, inform my students what is the strongest argument against some view, and so on. I can do these things only because there already exists a bundle of expectations about what a "professor" is, such that it is intelligible and appropriate for me to act in these ways on these relationships. ${ }^{7}$

On the RIM, then, structural transformation is made possible when all individuals throughout the entire system push the boundaries of their social roles, even outside of acute conflicts involving specific powerful agents. When a professor encourages students to adopt genderneutral language or signs an open letter to university administration, she stands in the right sort of relationship to be addressing these others in virtue of her role. Yet at the same time, she also pushes its boundaries by attempting to achieve something outside of it: by influencing the way that others carry out their roles (as students, deans, etc.). In effect, she alters the expectations issuing from the role-segments of which she is a party, thereby opening up new options by reweighting the stakes. A sympathetic academic dean who would otherwise be squeezed by other administrative prerogatives, for instance, has more "elbow room" (McKeown 2015) to maneuver when she is backed up by an open letter signed by the faculty, along with student protests, alumni letters, and media coverage. Similarly, every time a child sees her peers wearing gender-transgressive clothing or hears her caretakers recounting counter-stereotypical narratives, she acquires new understandings of what is expected from her by different rolesegments, making it easier for her to challenge gender norms.

The simultaneously constraining and enabling character of social roles, then, provides a more holistic picture of structural transformation. Social systems are resistant to change, because different structures work in tandem to restore equilibrium. Instead, pressure must be applied throughout the entire system, so as to produce either slow, incremental evolution toward a new equilibrium or else to prepare the way for more ruptural changes (often brought about by crisis) and enable them to "stick". To be sure, radical wholesale transformation usually does require historical developments on the order of an Industrial Revolution or a World War that eventually set off major ruptures. But these are rare and cannot be effected at just any time; moreover, even their transformative power depends on conditions long in the making - and this is the process to which we are responsible for contributing via boundarypushing. ${ }^{8}$ No theory of responsibility or ethics can mandate or predict what is empirically needed for transformative social change. (Of course, at extraordinary historical moments, there

\footnotetext{
${ }^{6}$ One might make the Panglossian objection that the overall system already is the best that it could possibly be, and that current injustices are simply unavoidable tradeoffs. But this is simply defeatism, or complacency which we should reject.

${ }^{7}$ See also fn. 13 for an example of how a role can be a strategic resource and "precondition" of organizing for structural change.

${ }^{8}$ Enrique Dussel (2008) writes: "[R] evolutionary processes of human history can progress for centuries without appearing as visible. It is true that one can prepare for and advance the revolution, but only within the limits of determined time... To believe that a revolution is possible before its time is as naive as not noticing - when such a revolutionary process has begun - its empirical possibility. History matures with an objective rhythm that does not necessarily enter into personal biographies no matter how voluntaristically we might wish.”
} 
will be correspondingly extraordinary opportunities to stretch boundaries in more radical ways, to abolish old roles, and establish novel ones in service of a new social order.) But the RIM explicates how and why there are moral claims on all of us at any given time to exercise our individual agency throughout the system so as to bring about the conditions of possibility for transformative change. That possibility is located in the social roles we occupy: while social roles function to maintain structures, the very features that make that possible also render them into resources for changing those structures.

\subsection{The Question of Justification: Why Am I Accountable?}

An acceptable model must clearly explain why each and every particular agent is expected to contribute to structural transformation. Because, by definition, structural injustice is maintained by ordinary behavior that would not be wrong in and of itself, justification must be given for why a particular agent may not simply keep doing as she is doing.

Young recognizes that individuals often avoid responsibility by declaring that it is "not their job" to address poverty, racism, and so on - it is the state's job, perhaps, or the job of someone working for a charity (Young 2011). Given the forward-looking orientation of the SCM, moreover, it might seem that the burdens should indeed fall on these more powerful agents with greater capacity for enacting change. In response, Young argues that qualitatively different contributions are required from different social positions: although governments are more powerful agents, for instance, they will not act unless pressured by the actions of citizens.

While this reply goes some way toward answering the question of justification, I do not think it goes far enough. It remains far too easy for individuals to believe that other people can and should do the work of promoting structural change, and that they are morally in the clear so long as their causal contributions are not blatantly wrong. If, say, a white, middle-class, heterosexual, cisgender, able-bodied man does not have any personal stake or interest in combating these various oppressions, he may agree that these are things that are wrong with the world but not feel compelled to act on it, so long as he himself does not engage in overtly prejudiced, exploitative, or biased ways.

The RIM answers the question of justification differently, in two ways. First, as described in the previous sub-section, structural transformation requires applying pressure everywhere in the system, i.e. boundary-pushing in all social roles. Second, it is everyone's job to fight injustice because it is already their job to perform their roles well. In other words, it is one's job not just to be a teacher, but to be a good teacher. This second justification is particularly important for individuals who do not feel the force of injustice because they are personally unaffected by it, and who would otherwise try to reject the burden of structural transformation.

To put a finer point on it, it is part of doing one's job well to strive towards a role-ideal. A $\operatorname{good} X$, where $X$ is some social role, is one who makes all the (countless, tiny) decisions required to perform that role in accordance with a substantive role-ideal. Constructing a roleideal requires critical reflection on the purposes and aims of the role, how it might be modified to better achieve them, what auxiliary roles should be created or modified, and how to collaborate with others possessing similar aims. ${ }^{9}$ For example, it is simply part of being a good teacher to ask: "What course offerings are we missing? What trends are shaping higher education today, and what political and economic conditions are affecting my students' ability

\footnotetext{
${ }^{9}$ See Herzog (2018) for an exemplary analysis of this sort of critical reflection, which she terms "transformational agency," in organizational contexts.
} 
to learn? What committees or local organizations should I serve on to address the problems I see?" While such reflection is not printed in the formal job description (and of course, many roles are entirely informal), it goes without saying that a good $X$ must consider such questions. But - and this is the point - it is also precisely by asking these questions that one pushes the boundaries of one's role, and thereby contributes to structural transformation. In other words, because social structures are built up out of interlinked social roles that together constitute a stable system, modifying any social role constitutes making some modification (however slight) to the overall system. ${ }^{10}$ Whether or not a person acknowledges that present social structures are unjust, then, occupying a social role makes them responsible for boundarypushing of the sort that makes social change possible.

\subsection{The Question of Specification: What, Specifically, Am I Accountable for?}

An acceptable model must provide specific guidelines as to what sorts of actions individuals are expected to take. The SCM does well in providing such guidelines. While declining to stipulate any exact algorithm for calculating what to do, Young identifies four "parameters for reasoning" for people differently-situated with respect to structural injustice. She recommends that: 1) agents with the power to alter structural processes should try to do so, 2) agents with privilege, i.e. who benefit from structural processes though they lack the power to alter them, should use their more ample resources to change their habits and support others' efforts, 3) agents with an interest in changing the system, i.e. the victims of structural injustice, should make efforts to publicize and organize around their plight, and 4) agents in existing organizations with collective ability should strive to direct their membership toward action.

These parameters are very useful. But one might stand in the same relation with respect to multiple injustices, or in different positions with respect to different injustices. An intersectional perspective takes seriously the variety of oppressions that make up structural injustice, as well as the ways in which the same agent may be simultaneously perpetrator, bystander, and victim, and hence possess cross-cutting and different degrees of power, privilege, interest, and collective ability. Thus it can still feel bewildering to know where to start.

Social roles, however, take us further towards specification because they are rich in content, which allows them to be action-guiding. For every role, there is some intuitive, salient, and relatively circumscribed range of associated actions. For instance, merely by understanding what a "teacher" is, we can reasonably expect a person who is a teacher to act on the questions listed above. We need not, however, expect her to process the thousands of untested rape kits that wait untouched in hospitals, or to feed homeless people - though there are others occupying roles in which they are the ones expected either to perform these tasks, create new roles for performing them, or find people to fill unoccupied roles. By reflecting on the

\footnotetext{
${ }^{10}$ The point here is that on the RIM , every person is subject to claims to act in ways that constitute changing the system, because every person already enacts a small part of the system in virtue of performing their social roles. Of course, different roles will differ in the amount of impact they can have on the system, even though it is trivially true that modifying any role will thereby modify the system. However, every person will occupy at least one and likely several roles (in virtue of their employment, familial relations, or social identities) that are more deeply implicated in one or more of the fundamental economic and social relations that generate structural injustice. Unfortunately, it is certainly the case that roles can be modified in ways that lead to more rather than less injustice, and there will be substantive disagreement about how and in what direction boundaries should be pushed in order to perform a role well (see the third objection in Section 5). But it is in virtue of occupying social roles that everyone is morally required to engage with substantive problems of injustice, i.e. they are responsible for injustice. I would like to thank an anonymous reviewer for pushing me to clarify these points.
} 
constitutive role-segments of a given role, i.e. the specific forms of power, capital, or demands to which one is entitled in the relationship through that role, one can carve out a range of potential boundary-pushing actions. Of course, the nature of actual relationships will differ greatly, and boundaries are drawn in very different places: merely signaling some political view with a lawn sign might count as "pushing it" in one context (in the role of "neighbor"), while marching in the streets to disrupt traffic might be called for in another (in the role of "citizen"). But the act of tending one's lawn is as clearly intelligible and appropriate for the role of neighbor as is attending public demonstrations for the role of citizen.

\subsection{How Much Am I Accountable for?}

An acceptable model must navigate between demanding too much and too little of individual agents. When we endeavor to truly appreciate the fullness of structural injustice, it can seem that we would never be able to fulfill all that morality demands, and that our attempted excuses - personal projects, special relationships, and so on - are just that, in comparison to the colossal weight of injustice. Yet if we unconditionally protect these projects and relationships, then the work of rectifying structural injustice can appear merely optional, rather than required. This licenses complacency and conservatism, and seems deeply disrespectful to the victims of injustice.

Young acknowledges the specter of demandingness as "a truth we should pause at" and she recognizes that agents can justifiably feel overwhelmed and paralyzed (Young 2011). Her solution is to stress again that responsibility on the SCM is collectively discharged, and that individuals are required to join with others - no individual is expected to fix structural injustice on her own. Moreover, Young is open to considerations of "what is possible and reasonable to expect" in order for responsibility to be "practically manageable"; one function of the parameters of reasoning is to prioritize and limit what can be expected of individuals (Young 2011). As they stand, however, the parameters are silent on just how much of individuals' time, effort, and resources should be devoted to discharging their responsibility for structural injustice. Without some sense of this, however, it is difficult to see what difference it makes to be responsible or not. Once it is established that I am responsible for structural injustice, what can I be expected to do differently?

This is where the other features of social roles point in a promising direction. As described in Section 3, even though roles contain much action-guiding content, they are never fully specifiable in complete detail; moreover, every individual at any given time simultaneously occupies a multiplicity of varying types of roles. The indefinability, multiplicity, and flexibility of roles means that individuals are always at any given moment confronted with the need to make decisions about how best to approximate their role-ideal(s) and which of their roles to prioritize in a particular situation. Many different reasons - e.g. ease, efficiency, familiarity, personal preference - go into the infinitely many decisions that constitute role performance (and a sizeable number are made without conscious thought). Being accountable for structural injustice places the demand on individuals to add a further reason into this set: whether and how one can push the boundaries of one's role in the right direction. In short, it means performing all one's roles with a raised consciousness.

There is a sense in which accountability for injustice is thus extremely demanding, because one is required to pursue it in all of one's roles. This is apt, because structural injustice comprises social structures of all types at all levels, and these must all be transformed: not just laws and workplace policies, but also gender roles within the family. Yet there is another sense 
in which being accountable is still manageable, because that responsibility is discharged through work that one is already always performing. Returning to the case of parents choosing schools for their children, for instance, it might be incumbent on them - in the process of researching or visiting potential school districts - to include neighborhoods in the search that they would otherwise have not considered. ${ }^{11}$ Doing so is part of being a good parent who recognizes how different social environments afford opportunities for cultivating different moral values, interpersonal skills, and epistemic capacities in children - and the social consequences thereof. Of course, the ultimate decision will involve a complex weighing of all the trade-offs stemming from all the different roles at play, but what the RIM establishes is that we must as far as possible carry out our roles with consideration of how to do so in line with role-ideals aimed at structural transformation.

In sum, it is true that performing roles with a raised consciousness is demanding because it requires time and effort. But performing a role well always requires this kind of time and effort. For recall that this is precisely what one does in constructing and pursuing a role-ideal: one critical reflects on how best to perform it. What the RIM claims is just that an assessment of how "best" to perform the role must include some assessment of whether and how it contributes to structural injustice. Unlike the SCM, then, which seeks to justify extra-role burdens grounded in a "general responsibility for justice" (Young 2011), the RIM locates these burdens within a person's roles - they are burdens that she is already committed to shouldering.

\subsection{The Question of Sanctions: How Can I Be Held Accountable?}

Finally, an acceptable model must provide an account of the sanctions licensed by responsibility for structural injustice. Without sanctions, responsibility would be toothless; it would make no difference whether one were responsible or not.

Young takes great pains to assert that blame and punishment - the traditional responses associated with responsibility - are not at issue in the SCM. However, the SCM does not offer an account of what sorts of criticism would be warranted. Although Young distinguishes between "blaming," on the one hand, from "criticizing and holding accountable," on the other, she does not provide further explanation of this distinction (Young 2011).

On the RIM, the question of sanctions is already built into the concept of a role itself, since to occupy a role just is to be subject to expectations maintained by internal and external sanctions. As with the SCM, holding agents accountable for structural injustice does not amount to blaming or punishing them, and hence does not require meeting the conditions for ascribing attributability; rather, it is (as on all models of responsibility as accountability) to assign them the burdens of changing that structure. Negative sanctions that are normally

\footnotetext{
${ }^{11}$ I am grateful to an anonymous reviewer for this example. In an article for the New York Times, Nikole HannahJones writes eloquently of the effects of segregation and gentrification in Brooklyn, N.Y. and her firsthand knowledge of the life-altering effects of being one of very few Black children sent to a Whiter, richer school through a voluntary desegregation program in Iowa. She recounts how she persuaded her husband to enroll their daughter in a low-income public school: "One family, or even a few families, cannot transform a segregated school, but if none of us were willing to go into them, nothing would change. Putting our child into a segregated school would not integrate it racially, but we are middle-class and would, at least, help to integrate it economically. As a reporter, I'd witnessed how the presence of even a handful of middle-class families made it less likely that a school would be neglected" (Hannah-Jones 2016). In my terminology, Hannah-Jones is pushing the boundaries of her role as "parent" by expanding it to include consideration of the effects of her actions on other parents and children in her community.
} 
appropriate for addressing suboptimal performance, then, might also be applied whenever agents fail to do enough to contribute, whenever those sanctions consist of assigning them the burdens of boundary-pushing. For example, a teacher might be encouraged or mandated by others to diversify a syllabus, whether or not she is blameworthy for not doing so previously. This sanction is clearly an appropriate thing to require of a "teacher" to improve her performance qua teacher, but simultaneously one that requires the teacher to push beyond the status quo of what is currently expected from the role in ways that contribute to greater structural transformation. To take another example, people are appropriately subject to reminders from others of their role(-ideals), i.e. of the fact that they should strive to push the boundaries of their roles in ways that contribute to rectifying injustice. Such role-reminders function to assign the burden of structural change, and are justifiable without the conditions that are needed for ascribing attributability. ${ }^{12}$

Psychologically, invoking social roles is likely to be motivationally effective, since people identify strongly with at least some of their roles. Moreover, the multiplicity of roles occupied by any given agent affords a variety of options for engaging her in the boundary-pushing work of structural transformation through some role or other. Rather than accusing a person of complicity in structural injustice, which is likely to provoke defensiveness, one can instead cite exemplary role models, organizational mission statements, or other discourses that serve to prime a person's role-ideals. Role-ideal reminders, then, are an example of an accountability practice for structural injustice that is normatively justified and practically effective even where blame and punishment are not.

\section{Objections}

Perhaps the most obvious and challenging objection is that some roles are positively unjust in and of themselves. Isn't the RIM committed to the counterintuitive claim that people occupying these roles have a responsibility to perform unjust acts?

Not necessarily. For social roles are, as a general matter, contextually bound. There used to be chattel slave-owners, but now there are not. There was a time at which there was no such thing as "electricians" or "web designers," but now there are. It is thus quite an unremarkable fact that roles enter and disappear from existence in flux with changing institutions, technology, culture, and fads. It might easily be the case, then, that to be "a good $X$ " in some cases is to work to bring about the conditions under which Xs would no longer exist. It is not a contradiction in terms, then, to speak of "a good slave-owner" as it would be "a good murderer." Moreover, we should not underestimate the creative ways in which individuals can strategically make use of traditionally-defined roles in new and transgressive ways. For example, women during the Salvadoran civil war (a contingent of which believed that rejecting traditional domestic gender roles was part and parcel of building a new socialist society) used their roles as wives, mothers, and daughters to mobilize women's organizations protesting the military dictatorship's economic policies. ${ }^{13}$ Finally, it is usually the case that the social

\footnotetext{
${ }^{12}$ For more on reminders as a practice of accountability, see Zheng (2018).

${ }^{13}$ A representative of the Women's Association of El Salvador (AMES) writes: "Women's mobilizations in defense of, and in solidarity with, the struggles of men have grown from day-to-day, helping to expose the true nature of the military regimes. The defense of women's traditional role, though conceived within a liberal context and subject to penetration by bourgeois ideology, is a precondition for these mobilizations of women: it is not easy for the state to repress those who, as mothers, wives, daughters, confront it in the very roles which constitute a pillar and foundation of domination" (New Americas Press 1989).
} 
institutions in which roles are embedded subscribe to higher values that provide resources out of which individuals can construct role-undermining role-ideals. Even, say, a National Security Agency (NSA) whistleblower who leaves or "betrays" her role might argue instead that her actions are in a deeper sense required by the principles that the NSA itself is sworn to protect.

But, one might protest, was it really qua good NSA officer that the whistleblower acts? Is it not that the boundary-pushing behavior derives from duties attaching to pure moral agency itself, irrespective of any roles? To this I say: Yes, so it is - and that is precisely the point. The loyal whistleblower's actions are an exercise of individual moral agency - but it is intelligible and morally illuminating to understand her (as many in such cases commonly do profess) to be doing so through her role, using the distinctive resources and powers that she claims through it. Thus it is through pursuing a specific role-ideal that a person uses her agency to reshape structure.

This leads to a third objection. How does one know what "a good $X$ " is? There is significant disagreement on such questions. A Republican might say that a good "citizen" should vote for Trump, while a Democrat would say that a good citizen should vote for Clinton, and others would say that a truly good citizen should vote for neither or that "citizen" is a role that should be rejected altogether.

It is true that the RIM does not itself adjudicate between competing role-ideals. But it is not the job of a theory of responsibility to issue such judgments: we do not get answers to such substantive questions for free. A theory of responsibility will not tell us what our first-order duties are - whether those are to maximize utility, cleave to the Categorical Imperative, overthrow capitalism, or what - but only the conditions under which, and the grounds on which, our failing to uphold those duties makes us appropriately subject to sanctions/burdens. Although it does not provide answers, what the RIM does is call upon individuals themselves to confront such questions of structural injustice via reflection upon their role-based duties and ideals, and it furnishes the ethico-political framework within which no individual is allowed to shirk the requirement of engaging in such substantive disagreements. For such disagreements generate the potential for structural change. Individuals cannot avoid responsibility for structural injustice because they each occupy at least one (and likely many) role(s) whose good performance demands that they consider such questions, and which requires dialoguing with others. This is what Young, following Hannah Arendt, calls a genuinely political responsibility (Young 2011): it is political because it requires that people exchange, entertain, and defend different views about their shared social conditions. In disagreeing over role-ideals, then, one is engaging in politics. But one is doing so at the point where structure meets agency, such that the individual's choice of how to perform that role contributes to the overall project of structural transformation.

Finally, one might object that it is unfair to be assigned a role that one did not choose, and to be expected to perform it well if one does not endorse its end. Why should a person care about performing well some role which she did not choose and does not endorse? The first thing to note in reply is that everyone is bound to care about some social role or other. Human beings, as Aristotle noted so long ago, are social animals; they cannot live except enmeshed in social relations. Thus, for whichever relations matter most to a person - be they familial, friendly, collegial, or geographical - there will always be some social role, to which is attached a roleideal that that person will be motivated to pursue. And in virtue of pursuing this roleideal, that person will have (internalist) reason to engage in transformative work. 
The second thing to note, however, is that being assigned a role logically entails being expected to perform it well. Such an expectation holds whether the occupant cares about it or not; even a burger-flipper must form some role-ideal ${ }^{14}$ according which the job could be done better or worse, even if she is not motivated to work toward it. To be sure, some people will not perform their roles well. No theory of responsibility can guarantee that; indeed, a theory of responsibility is needed precisely because people will not always act well. And there may be some roles where mediocre or poor performances simply do not matter, because the roles themselves are trivial. But it is still simply part of the logic of occupying a role that one is subject to the expectation of performing it well, and has (externalist) reason to do it well. ${ }^{15}$ What the RIM provides is a model of how individual role performance contributes to structural change.

\section{Conclusion}

In this paper I have defended a new theory of individual responsibility for structural injustice: that we are responsible through and in virtue of our social roles. I have argued that any acceptable theory should address the following challenges: describing how social change is possible, justifying demands on particular persons, guiding action by specifying a range of options, being appropriately but not overly demanding, and licensing critical moral sanctions. And I have claimed that the familiar concept of social roles - the interface between structure and agency - is ready-equipped with all the features we need.

Acknowledgments I am grateful for feedback from audiences at the 2017 International Conference on Iris Marion Young at the University Paris 1- Panthéon Sorbonne, Ethical Theory and Moral Practice 20th Anniversary Conference at the University of Pavia, and the 3rd Role Ethics Network Workshop at the Open University. I would also like to acknowledge Simeon Newman and two anonymous reviewers for helpful comments on an earlier version of this paper.

Open Access This article is distributed under the terms of the Creative Commons Attribution 4.0 International License (http://creativecommons.org/licenses/by/4.0/), which permits unrestricted use, distribution, and reproduction in any medium, provided you give appropriate credit to the original author(s) and the source, provide a link to the Creative Commons license, and indicate if changes were made.

\section{References}

Baker WE, Faulkner RR (1991) Role as resource in the Hollywood film industry. Am J Sociol 97:279-309 Black M (1961) The social theories of Talcott Parsons: a critical examination. Prentice-Hall, Englewood Cliffs Blackman R (2017) Roles ground reasons; so internalism is false. PEA Soup. http://peasoup.us/2017/01/rolesground-reasons-internalism-false-reid-blackman/. Accessed 28 Apr 2018

Boxill BR (2003) A Lockean argument for black reparations. J Ethics 7:63-91

\footnotetext{
${ }^{14}$ One could argue, moreover, that a good minimum wage worker is not only someone who performs tasks competently and efficiently, but who also unionizes her co-workers or otherwise demands better working conditions that would enable those tasks to be performed better and more sustainably.

${ }^{15}$ For some further defense of this claim, see Blackman (2017).
} 
Butt D (2009) Rectifying international injustice: principles of compensation and restitution between nations. Oxford University Press, Oxford

Calder T (2010) Shared responsibility, global structural injustice, and restitution. Soc Theory Pract 36:263-290

Callero PL (1994) From role-playing to role-using: understanding role as resource. Soc Psychol Q 57:228-243. https://doi.org/10.2307/2786878

Collins PH (1990/2000) Black feminist thought: knowledge, consciousness, and the politics of empowerment. Routledge, New York

Collins S (2013) Collectives' duties and collectivization duties. Australas J Philos 91:231-248. https://doi. org/10.1080/00048402.2012.717533

Collins S, Lawford-Smith H (2016) The transfer of duties: from individuals to states and back again. In: Brady M, Fricker M (eds) The epistemic life of groups. Oxford University Press, Oxford, pp 150-172

Connell RW (1979) The concept of role and what to do with it. Australian and New Zealand J Sociol 15:7-17. https://doi.org/10.1177/144078337901500302

Dahrendorf R (1968) Homo sociologicus. In: Essays in the theory of society. Routledge \& K. Paul, London, pp 19-87

Dussel ED (2008) Twenty Theses on Politics. Duke University Press, Durham

Feinberg J (1968) Collective responsibility. J Philos 65:674-688. https://doi.org/10.2307/2024543

French PA (1984) Collective and corporate responsibility. Columbia University Press, New York

Goffman E (1959) The presentation of self in everyday life. Doubleday, Garden City

Gross NC, Mason WS, McEachern AW (1958) Explorations in role analysis: studies of the school superintendency role. Wiley, New York

Hannah-Jones N (2016) Choosing a School for My Daughter in a Segregated City. New York Times

Haslanger S (2015) Distinguished lecture: social structure, narrative and explanation. Can J Philos 45:1-15. https://doi.org/10.1080/00455091.2015.1019176

Held V (1970) Can a random collection of individuals be morally responsible? J Philos 67:471-481

Herzog L (2018) Reclaiming the system: moral responsibility, divided labour, and the role of organizations in society. Oxford University Press, Oxford

Isaacs T (2011) Moral responsibility in collective contexts. Oxford University Press, New York

Kutz C (2000) Complicity: ethics and law for a collective age. Cambridge University Press, Cambridge

Lavin C (2008) The politics of responsibility. University of Illinois Press, Champaign

MacIntyre A (1999) Social structures and their threats to moral agency. Philosophy 74:311-329

May L (1992) Sharing responsibility. University of Chicago Press, Chicago

McGary H (1986) Morality and collective liability. J Value Inq 20:157-165

McKeown MC (2015) Responsibility without guilt: a Youngian approach to responsibility for global injustice. UCL (University College London)

Mellema G (2016) Complicity and moral accountability. University of Notre Dame Press, Notre Dame

Miller D (2007) National responsibility and global justice. Oxford University Press, Oxford

New Americas Press (1989) A dream compels us: voices of Salvadoran women. South End Press, Boston

Parsons T (1951/1991) The social system. Routledge, London

Schmidtz D, Goodin RE (1998) Social Welfare and Individual Responsibility: for and against. Cambridge University Press, Cambridge

Singer P (1972) Famine, affluence, and morality. Philos Public Aff:229-243

Young IM (2011) Responsibility for justice. Oxford University Press, New York

Zheng R (2016) Attributability, accountability, and implicit bias. In: Saul J, Brownstein M (eds) Implicit bias and philosophy, Vol 2. Oxford University Press, New York, pp 62-89

Zheng R (2018) Bias, structure, and injustice: A reply to Haslanger. Fem Philos Q 4:Article 4. https://oi. org/10.5206/fpq/2018.1.4 